\title{
Bystander cricothyrotomy with ballpoint pen: a fresh cadaveric feasibility study
}

\author{
Ulrich Kisser, ${ }_{1}^{1}$ Christian Braun, ${ }^{2}$ Astrid Huber, ${ }^{1}$ Klaus Stelter ${ }^{3}$
}

- Additional material is published online only. To view please visit the journal online (http://dx.doi.org/10.1136/ emermed-2015-205659).

${ }^{1}$ Department of Head and Neck Surgery, LudwigMaximilians-University Munich, Munich, Germany

${ }^{2}$ Institute of Legal Medicine and Forensic Sciences, Ludwig Maximilians-University Munich, Munich, Germany ${ }^{3}$ HNO Zentrum Mangfall-Inn, Rosenheim, Germany

\section{Correspondence to} Dr Ulrich Kisser, Klinik und Poliklinik für Hals-Nasen- und Ohrenheilkunde,

Marchioninistraße 15, München 81377, Germany; Ulrich.kisser@med.unimuenchen.de

Received 23 December 2015 Revised 29 February 2016

Accepted 19 March 2016 Published Online First 19 April 2016
CrossMark

To cite: Kisser U, Braun $C$, Huber A, et al. Emerg Med J 2016;33:553-556.

\section{ABSTRACT}

Objective In motion pictures and anecdotal reports, ballpoint pens have been used for life-saving cricothyroidotomies. The objective of this study was to examine the widespread belief that ballpoint pens can perforate the skin and cricothyroid ligament and could be used as substitute tracheostomy sets in an emergency setting.

Methods Three different ballpoint pens were examined regarding their inner diameter, their demountability to form a cannula and their airflow properties. Ten medical laypersons were asked to try to puncture the trachea through the skin and the cricothyroid ligament in 10 fresh cadavers just using the ballpoint pens.

Results Two of three pens had inner diameters of $>3 \mathrm{~mm}$ and were both suitable as cannulas in a tracheotomy. All participants could perforate the skin with both ballpoint pens. However, almost no one could penetrate through the cricothyroid ligament or the ventral wall of the trachea, except for one participant. He performed the tracheostomy after three attempts in $>5$ min with a lot of patience and force.

Conclusions A cricothyroidotomy just with a ballpoint pen is virtually impossible. First, the airflow resistance in commercially available ballpoint pens is too high to produce effective ventilation. Second, the cricothyroid ligament is too strong to be penetrated by ballpoint pens.

\section{INTRODUCTION}

Acute airway obstruction is a rare but potentially life-threatening situation. In-hospital techniques recommended for this situation include tracheostomy, needle cricothyroidotomy and surgical cricothyroidotomy. In the prehospital setting, however, none of these techniques may be available to bystanders, and non-medical objects may need to be adapted in order to perform cricothyroidotomy. There is a lack of literature examining surgical cricothyroidotomy in the emergency setting, ${ }^{12}$ and even fewer papers discussing the use of nonmedical equipment. ${ }^{3-5}$ The ideal substitute must be readily available, sharp and narrow enough to puncture the skin and cricoid membrane, wide enough to allow gas exchange $(>3 \mathrm{~mm})$, long enough to cannulate the cricothyroid membrane and still allow mouth-to-tube ventilation, rigid enough not to collapse and it must have low airway resistance. $^{5}$

In various motion pictures (ie, SAW6), medical TV serials (Dr House, Season 4) and internet chatrooms, ballpoint pens have been used for a lifesaving cricothyroidotomy. Even some medical textbooks recommend the use of the barrel of a ballpoint pen as a cannula. ${ }^{67}$

\section{Key messages}

What is already known about the subject?

- Popular media and even some textbooks have suggested that a ballpoint pen can be used to perform a cricothyrotomy. Reports of improvised cricyothyrotomy in the medical literature with a pen or other object all involved the use of a blade first.

\section{What might this study add?}

- In this study using fresh cadavers, we demonstrate that a cricothyroidotomy using just a ballpoint pen is nearly impossible; the pen cannot penetrate the cricothyroid membrane without significant damage, and the resistance to flow in the cannula prevent effective ventilation.

However, there is uncertainty about whether it is possible to perform a cricothyroidotomy and maintain gas exchange just with a ballpoint pen. ${ }^{5}$ The senior author of this article (KS), an experienced head and neck surgeon, tried to perform a cricothyroidotomy in a fresh cadaver just with the MontBlanc pen before the official start of the study, but could not penetrate the cricothyroid ligament. This study examines a variety of commercially available ballpoint pens regarding their suitability for cricothyroidotomy performed by bystanders.

\section{MATERIALS AND METHODS}

The primary outcome of the study was to prove that a bystander cricothyroidotomy just using a ballpoint pen is possible. In the first step, three different ballpoint pens were chosen and the following parameters examined: inner diameter, demountability to form a cannula and airflow in spirometry using the dismantled pen. The following three commonly available ballpoint pens were used (compare figure $1 \mathrm{~A}-\mathrm{C}$ ):

- Schneider's K15, made of opaque plastic with $1.3 \mathrm{~mm}$ inner diameter

- Ritter PEN 01711 Classic, made of opaque plastic but with a removable metal jacket at the top

- Montblanc Masterpiece Platinum Line Classique made of black ebony with a removable metal jacket at the top

The clinical airflow was measured in all three ballpoint pens by flow spirometry of two healthy males, 38 years/29 years and two healthy females, 


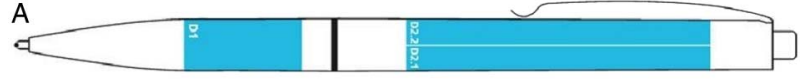

B

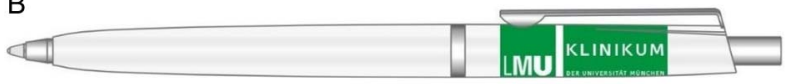

C

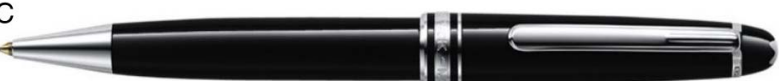

Figure 1 The three ballpoint pens involved in the study: Schneider's K15 (A), Ritter PEN 01711 Classic (B) and Montblanc Masterpiece Platinum Line Classique (C).

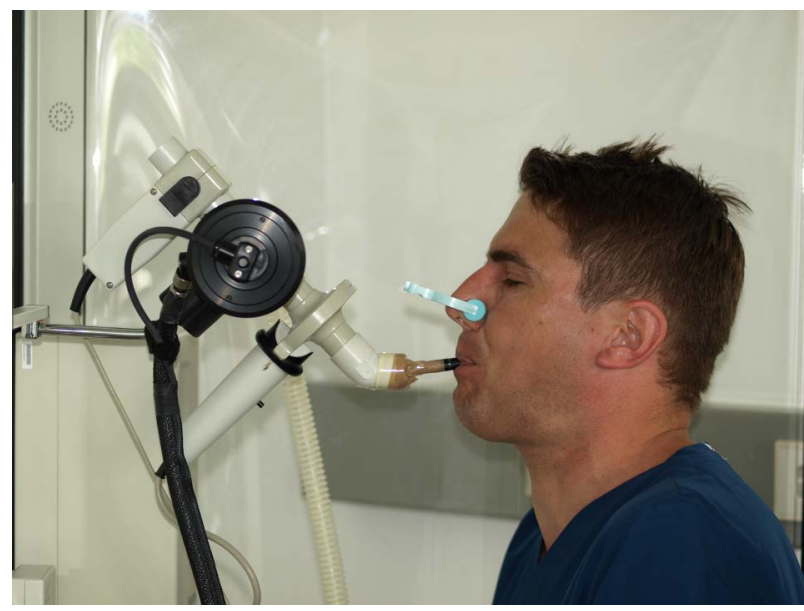

Figure 2 Forced expiration for 1 min through the dismantled pen attached to the plethysmograph.
27 years/26 years) with the MasterScreen Body Plethysmograph (VIASYS Healthcare, Germany). The participants had to breathe as hard as they could through the dismantled pen attached to the plethysmograph for $1 \mathrm{~min}$ (figure 2). According to the study of Owens et al, ${ }^{5}$ a precondition for the second part of the study was that the ballpoint pen provided an airflow of $>10 \mathrm{~L} / \mathrm{min}$. With the remaining ballpoint pens, 10 medical laypersons (lawyers, police men, law students, preclinical medical students, dentistry students) had to perform a cricothyroidotomy with one of the pens after randomisation by cards. No cadaver was older than 2 days. All cadavers were cooled to $8^{\circ} \mathrm{C}$ (no freezing). Cadavers were placed supine with their neck exposed. The thyroid cartilage was palpable in all cadavers by the supervising medical student $(\mathrm{AH})$, and the researcher of the forensic institute (CB). All participants were introduced by the two supervisors to place a cricothyroidotomy under the thyroid cartilage just with the pen as quickly as they can. Participants were expected to perform the procedure with no further specific training or advice. Only the thyroid cartilage was shown to the participants as the crucial landmark. Procedure time was defined as the time from when the participant touched the pen until they were happy with the placement of the pen barrel or the participant abandoned the procedure. A methodological workflow diagram is shown in figure 3 .

The study was approved by the local ethics committee (No 336-13). The relatives of the body donors were asked to give their informed consent. The complete cricothyroidotomy was recorded on video (a short example is shown in online supplementary video 1 ). The primary endpoint of the study was a successful or failed ventilation at the end. It was determined by the cadaver's chest rising in a mouth-to-pen resuscitation with cadaver's closed mouth and nose by the supervisors (figure 4). The

Figure 3 Workflow diagram.

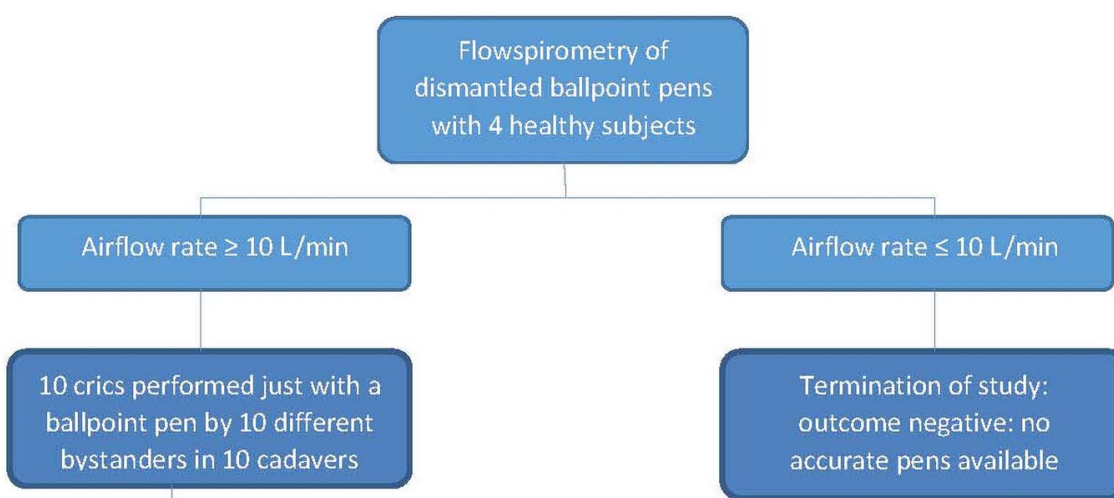

No chest rise in a mouth

to pen resuscitation:

primary outcome

negative 


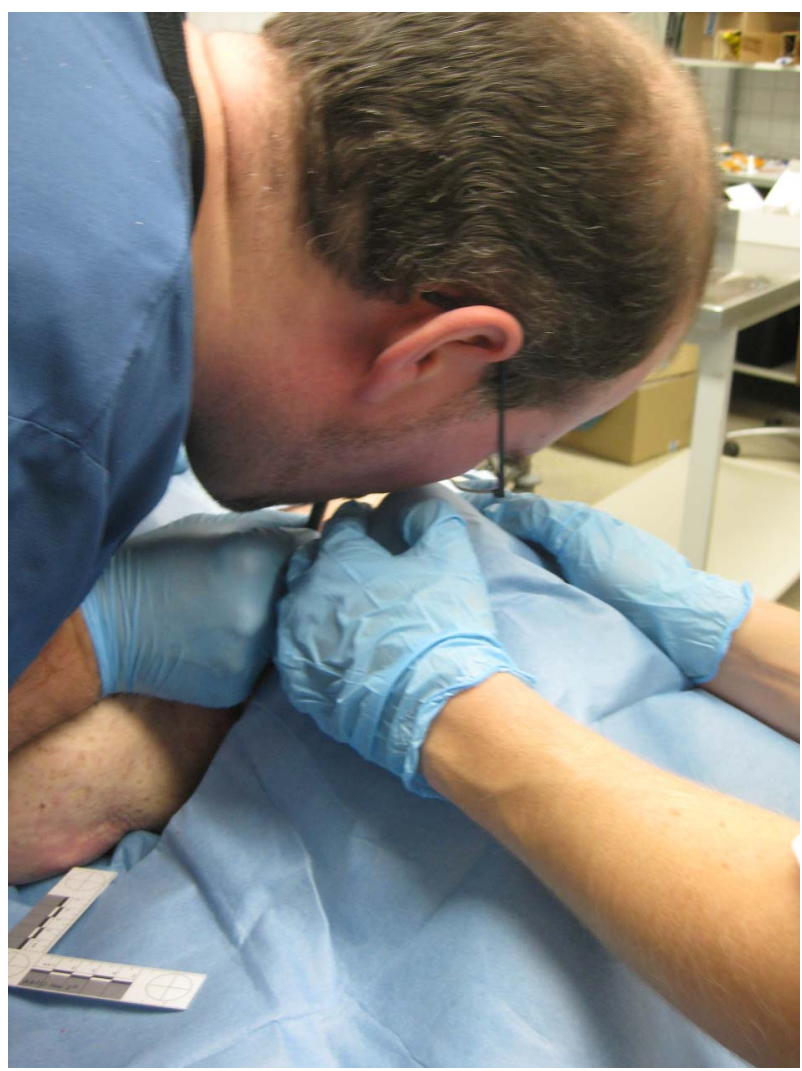

Figure 4 Mouth-to-pen resuscitation by the supervisors to determine the primary outcome (patient is not visible/identifiable).

collateral damage and penetrated tissue were evaluated afterwards by professional preparation of the larynx by a forensic medicine specialist.

Table 1 Best results of spirometry achieved by healthy subjects with three different pens

\begin{tabular}{llll}
\hline & $\begin{array}{l}\text { Minimum } \\
\text { diameter } \\
(\mathbf{m m})\end{array}$ & $\begin{array}{l}\text { FEV1 (forced 1 s } \\
\text { expiratory } \\
\text { volume) } \\
\text { (L/s) }\end{array}$ & $\begin{array}{l}\text { MV (volume after } \\
\text { 1 min forced } \\
\text { breathing) } \\
\text { (L/min) }\end{array}$ \\
\hline Pen (dismantled) & 1.3 & 0.58 & 6.8 \\
Schneider K 15 & 4.3 & 3.66 & 42.1 \\
Ritter 01711 Classic & 3.2 & 1.31 & 23.6 \\
Montblanc Masterpiece & 3.2 & & \\
\hline
\end{tabular}

\section{RESULTS}

The Schneider K15 ballpoint pen has a minimum inner diameter of $1.3 \mathrm{~mm}$ at the top. The maximum expiratory volume was $0.58 \mathrm{~L} / \mathrm{s}$. The maximum airflow was only $6.8 \mathrm{~L} / \mathrm{min}$, which is not enough for resuscitation. In contrast, the Ritter 01711 Classic Pen and the Montblanc Masterpiece Platinum had minimum inner diameters of $>3 \mathrm{~mm}$ and were both suitable as cannulas in a tracheotomy (table 1$)$.

According to the protocol, the study was continued with the Ritter Pen and the Montblanc Masterpiece. All participants were able to perforate the skin with both ballpoint pens; $60 \%$ of the participants performed the cricothyroidotomy too far caudally and tried to punctuate the trachea through the thyroid gland. Only 3 out of 10 perforated the skin over the cricoid. However, none of the participants could penetrate through the cricothyroid ligament or the ventral wall of the trachea except one, a 25 -year-old police man using the Ritter pen. More than 5 min, three attempts and a lot of patience and force were necessary. The pen perforated the cricothyroid ligament, damaged the cricoid cartilage and the tracheal back wall (table 2).

\section{DISCUSSION}

In the prehospital setting, standard medical equipment may not be available immediately. A ballpoint pen might seem suitable to perform cricothyroidotomy: many people carry one in their pocket, the extended cartridge inside should be sharp enough to puncture the skin and cricoid membrane, and the jacket should be wide enough to allow gas exchange. These theoretical considerations are inspired by motion pictures and legends of heroic lifesavers. The minimum inner diameter of a pen suitable for resuscitation should not be $<3 \mathrm{~mm}$. This could be confirmed by the results of our flow spirometric measurements and the study by Owens et al. ${ }^{5}$ Sufficient oxygen supply through cannulas of a smaller inner diameter can only be provided by modern jet ventilation systems, which are not available in the prehospital bystander situation. In the second part of the study, the ability of the remaining pens to penetrate the skin and trachea was tested. In a similar study of Neill and Anderson, nine untrained doctors and medical students were asked to try performing a cricothyroidotomy with a scalpel and a dismantled pen in embalmed cadavers. ${ }^{3}$ More than $50 \%$ were successful without major vessel injury, but in contrast with our study, the participants used a blade and the cadavers were embalmed, which results in an abnormal fixation of the skin and underlying cartilage. There is a case report of a ballpoint pen penetrating the chest of a 7-year-old girl when she fell onto its tip. ${ }^{8}$ Another

Table 2 Outcomes of 10 trials of cricothyroidotomy by 10 bystanders with a ballpoint pen

\begin{tabular}{|c|c|c|c|c|c|c|c|}
\hline No & Bystander's gender & Age & Procedure's duration & Pen & Cadaver specifications & Skin penetration & Outcome \\
\hline 1 & Female & 26 & $1.25 \mathrm{~min}$ & Montblanc & 86 years, BMI 25.5 & Cricoid & Neg. \\
\hline 2 & Female & 24 & $1.50 \mathrm{~min}$ & Ritter C & 76 years, BMI 31.6 & Trachea caudally thyroid gland & Neg. \\
\hline 3 & Male & 32 & $44 \mathrm{~s}$ & Montblanc & 68 years, BMI 37.1 & Thyroid gland & Neg. \\
\hline 4 & Male & 25 & $5.50 \mathrm{~min}$ & Ritter C & 86 years, BMI 25,4 & Cricoid & Pos. \\
\hline 5 & Female & 40 & $8.30 \mathrm{~min}$ & Ritter C & 63 years, BMI 27.3 & Cricoid & Neg. \\
\hline 6 & Female & 22 & $7.20 \mathrm{~min}$ & Montblanc & 68 years, BMI 26 & Thyroid gland & Neg. \\
\hline 7 & Female & 28 & $3.10 \mathrm{~min}$ & Ritter C & 86 years, BMI 29.4 & Thyroid gland & Neg. \\
\hline 8 & Female & 20 & $8.30 \mathrm{~min}$ & Montblanc & 82 years, BMI 33.7 & Trachea caudally thyroid gland & Neg. \\
\hline 9 & Female & 22 & $9.30 \mathrm{~min}$ & Montblanc & 74 years, BMI 25 & Cricoid & Neg. \\
\hline 10 & Female & 23 & $4 \min$ & Ritter C & 84 years, BMI 25.7 & Thyroid gland & Neg. \\
\hline
\end{tabular}

Bold text highlights the only successful trial of trachea penetration.

$\mathrm{BMI}$, body mass index. 
case report describes a penetrating injury of the cauda equina in a 10-year-old child who had fallen onto a wooden pencil. ${ }^{9}$ Jawish and Ponet ${ }^{10}$ reported on a child with torticollis due to the retention of a pencil cap that was lodged in the child's neck after having pierced the posterior wall of the pharynx. The Forensic Institute of Adelaide, Australia, could demonstrate the vulnerability of major neck vessels to ballpoint pens in a pig model. ${ }^{11}$ An intentional and targeted penetration of the trachea, however, does not seem to be comparable to these accidents. Six of 10 participants tried to puncture the trachea too caudally via the thyroid gland. Accordingly, the inaccuracy of using landmark techniques for reliable cricothyroid membrane identification has been shown by Bair and Chima. ${ }^{12}$ Except for one participant, no one was able to penetrate the trachea or the cricothyroid ligament. A police man successfully opened the trachea, but it took him three attempts and $>5 \mathrm{~min}$, which is too long for a successful resuscitation. Major collateral damage, like major vessel injury or nerve destruction, could not be observed.

\section{CONCLUSION}

A cricothyroidotomy just with a ballpoint pen is virtually impossible. A skin and ligament incision with another sharp tool (ie, pocketknife) is necessary first. Then, some ballpoint pens could be used as a ventilation cannula.

Acknowledgements We thank Fabian Kriner, the master preparator of the forensic institute, for his help with the cadavers.

Contributors UK and KS added substantial contributions to the conception and design of the work. $\mathrm{CB}$ and $\mathrm{AH}$ did the acquisition, analysis and interpretation of data. UK was drafting the work and revising it critically for important intellectual content. All authors approved the final version of the paper.

Funding The MontBlanc Masterpiece Pen was bought by the Senior Author (KS).
Competing interests None declared.

Ethics approval The study was approved by the local ethics committee (University of Munich, No 336-13). The relatives of the body donors were asked to give their informed consent.

Provenance and peer review Not commissioned; externally peer reviewed.

\section{REFERENCES}

1 Fikkers BG, van Vugt $S$, van der Hoeven JG, et al. Emergency cricothyrotomy: a randomised crossover trial comparing the wire-guided and catheter-over-needle techniques. Anaesthesia 2004;59:1008-11.

2 Davis DP, Bramwell KJ, Hamilton RS, et al. Safety and efficacy of the rapid four-step technique for cricothyrotomy using a Bair Claw. J Emerg Med 2000;19: 125-9.

3 Neill A, Anderson P. Observational cadaveric study of emergency bystander cricothyroidotomy with a ballpoint pen by untrained junior doctors and medical students. Emerg Med J 2013;30:308-11.

4 Adams BD, Whitlock WL. Bystander cricothyroidotomy performed with an improvised airway. Mil Med 2002;167:76-8.

5 Owens D, Greenwood B, Galley A, et al. Airflow efficacy of ballpoint pen tubes: a consideration for use in bystander cricothyrotomy. Emerg Med J 2010;27: 317-20.

6 Weiss EA, Dorner HJ. Wilderness improvisation. Wilderness medicine: management of wilderness and environmental emergencies. 3 edn. Mosby Year Book, 1995.

7 Beers MH, Berkow R. The Merck manual of diagnosis and therapy. 17th edn. Merck Sharpe and Dohme Research, 1999.

8 Hoffman D, Sharieff G. Pencil stab wound results in pneumonia and pleural effusion. Am J Emerg Med 2000;18:345-6.

9 Piqueras C, Martínez-Lage JF, Almagro MJ, et al. Cauda equina-penetrating injury in a child. Case report. J Neurosurg 2006;104(4 Suppl):279-81.

10 Jawish R, Ponet M. Uncommon torticollis in children. Eur J Pediatr Surg 1991;1:307-8.

11 Byard RW, Cains GE, Gilbert JD. Use of a pig model to demonstrate vulnerability of major neck vessels to inflicted trauma from common household items. Am J Forensic Med Pathol 2007;28:31-4.

12 Bair $A E$, Chima R. The inaccuracy of using landmark techniques for cricothyroid membrane identification: a comparison of three techniques. Acad Emerg Med 2015;22:908-14. 